\title{
DIREITO E LITERATURA: A INSTITUIÇÃO DO EU E DO OUTRO
}

\section{LAW AND LITERATURE: THE CONSTRUCTION OF ME AND OTHER}

\author{
${ }^{1}$ Gretha Leite Maia
}

\section{RESUMO}

Um dos conceitos jurídicos fundamentais é o de sujeito de direitos. O objetivo desse estudo é relacionar o conceito de sujeito de direitos à instituição do eu e do outro e ressaltar o papel da literatura nessa instituição. Inicia-se com a proposta de compreensão do Direito como um sistema fundado a partir da bilateralidade, explorando também os conceitos de alteridade e identidade. Para esta parte da pesquisa foram trazidas as referências estabelecidas junto aos manuais de introdução ao Direito e aportes da antropologia geral e jurídica. A seguir, apresenta-se a literatura como uma ferramenta de leitura e escrita do mundo. Explora-se a ideia de que a construção (ou invenção) dos direitos humanos contou com participação da literatura engajada para a afirmação (ou estabelecimento) das condições subjetivas de aceitação do outro enquanto sujeito de direitos. Afirmada a possibilidade metodológica da pesquisa, foram analisadas duas obras da literatura moderna, uma na perspectiva universal e outra na perspectiva nacional. Assim, para demonstrar a função da literatura na instituição do eu e do outro, foram estudados os romances Os miseráveis, de Victor Hugo e Capitães dareia, de Jorge Amado. O estudo demonstra a contribuição da literatura no estabelecimento dos sujeitos tutelados pelo ordenamento jurídico, alargando a concepção estritamente jurídica do que seja um sujeito de direitos.

Palavras-chave: Direito, Literatura, Sujeito de direitos

\begin{abstract}
One of the fundamental legal concepts is person as its seem by the law. The aim of this study is to connect the concept of person and the concepts of "me" and "other," and highlight the role of literature in the construction of those concepts. The study starts with the proposal of understanding the law as a system founded on the reciprocity, and it also explores the concepts of otherness and identity. For this part of the research, we brought references established both in manuals of Law and in legal anthropology. After, it presents the literature as a tool to reading and writing the world. It explores the idea that the construction (or invention) of human rights had the participation of engaged literature. In this research, we analyzed two literary works, one in the universal perspective and another in the national perspective: Les Miserables, by Victor Hugo, e Capitães dareia, by Jorge Amado. The study demonstrates that literature contributes to the establishment of person protected by law, expanding the strictly legal conception of what is a "person" in law.
\end{abstract}

Keywords: Law, Literature, Person, Rights

\footnotetext{
${ }^{1}$ Doutora em Direito pela Universidade Federal do Ceará - UFC, Ceará (Brasil). Professora de Direito pela Universidade Federal do Ceará - UFC, Ceará (Brasil). E-mail: grethaleitemaia@ gmail.com
} 


\section{INTRODUÇÃO}

No estudo do Direito, em especial na disciplina de Introdução ao Direito, tem-se um conjunto de noções que se identificam por conceitos jurídicos fundamentais. Essa identificação se projeta nos manuais de introdução ao estudo do Direito, que sempre apresentam um capítulo ou mais para os conceitos jurídicos fundamentais. O tratamento doutrinário tem em comum a abordagem técnica, definidora, construída de modo a dotar o conceito de contornos. É, portanto, uma tentativa restritiva, que busca dar precisão a uma determinada noção. A hipótese dessa pesquisa é que a construção da ideia exata de um dos conceitos jurídicos fundamentais, o conceito de sujeito de direitos, exige um conhecimento mais amplo, que envolve a consolidação das perspectivas de eu e de outro, sem as quais não se compreende exatamente o que seja sujeito de direitos. A proposta desse estudo é a afirmação de que a literatura é um meio ideal para adquirir essa perspectiva.

Parte-se da revisão de literatura no que se refere ao conceito jurídico de sujeito de direitos. Após a sistematização de algumas propostas de conceito encontradas na doutrina de referência que normalmente é apresentada ao estudante de Direito no primeiro ano do curso, serão explorados os conceitos de bilateralidade, alteridade e identidade, buscados nos aportes da Antropologia geral e jurídica, áreas do conhecimento que também fazem parte da formação inicial do estudante de Direito. A seguir, explorou-se a aptidão da literatura para instalar um efetivo dispositivo de solidariedade entre os desiguais, no reconhecimento da condição de sujeito de direitos a um número amplo de indivíduos com múltiplas identidades. Para tanto, foram exploradas duas obras literárias: "Os miseráveis", de Victor Hugo, e "Capitães d'areia" de Jorge Amado. Representativas da literatura engajada, a personagem de Jean Valjean influenciou o discurso de humanização das penas nos séculos XIX e XX, enquanto os meninos do trapiche das areias de Salvador fizeram o Brasil repensar as questões envolvendo direitos das crianças e dos adolescentes.

\section{O CONCEITO DE SUJEITO DE DIREITOS}

Para a compreensão da proposta de Direito como um sistema de princípios e regras fundado na ideia de bilateralidade, o conceito de sujeito de direitos é considerado fundamental. A noção de direitos subjetivos era desconhecida até fins da Idade Média. Ferraz Júnior (1990, p.139) ensina que a dicotomia "direito objetivo" e "direito subjetivo" é moderna: enquanto os romanos a desconheciam, na Idade Média havia uma noção apenas semelhante, a de privilegium ou direitos especiais. A teoria dos direitos subjetivos foi 
elaborada sistematicamente na Alemanha, por doutrinadores do Direito Civil do séc. XIX. O conceito indica o titular de um direito, ao mesmo tempo em que institui as categorias de pessoa (ou personalidade) e capacidade (a medida da personalidade). Trata-se de uma qualidade conferida única e exclusivamente pelo ordenamento jurídico. Elaborado para garantir a liberdade de realizar trocas econômicas, o conceito de sujeito de direitos consolida- se ao tempo em que se consolida também o Estado moderno e o monopólio da jurisdição, com a estatização das fontes do Direito.

Reale (2001, p.227) diz que "o ordenamento jurídico destina-se a reger as relações sociais entre indivíduos e grupos" e que "as pessoas, às quais as regras jurídicas se destinam, chamam-se sujeitos de direitos". Sujeitos de direitos são os destinatários das normas jurídicas. Reale trabalha com a definição de Direito como "uma ordenação bilateral atributiva das relações sociais na medida do bem comum”. Montoro (2014) propõe o tratamento do Direito em cinco acepções: o Direito como ciência, o Direito como justo, o Direito como norma, o Direito como fato social e o Direito como faculdade, acepção esta que será examinada. Examinar o Direito como faculdade implica na apresentação do Direito como uma teoria dos direitos subjetivos, que vêm a ser, a partir de Savigny, um poder do indivíduo. Embora explore as teorias objetivistas, formalistas e a teoria do interesse, formulada por Ihering, Montoro (2014, p.506) conclui sua apresentação do tema com a proposta de direito subjetivo caracterizado pela relação de dependência entre o sujeito e o objeto dessa relação.

Reale e Montoro são estudos clássicos de introdução ao Direito no Brasil, ambos publicados no início dos anos 70 do século passado, sendo, portanto, obras com mais de 40 anos. Foram, ambos, professores catedráticos de Direito em universidades tradicionais, e representam uma proposta de conhecimento do Direito por conceitos igualmente tradicionais, derivados da doutrina civilista alemã que datam de mais de um século. É sob esse discurso tradicional, contornado e limitado, que os estudantes de Direito constroem suas primeiras lições. E é a possibilidade de enriquecer esse discurso um dos objetivos desse estudo.

Machado (2012, p. 11) define o direito subjetivo como um "efeito da incidência da norma ou prescrição jurídica. Efeito que a incidência da norma jurídica produz para alguém, para um sujeito". É sempre o direito de alguém, o direito em relação ao seu titular: "tem um sujeito e deve ser visto em função de um sujeito". Embora não se tenha debruçado mais detalhadamente sobre o conceito, essa definição nos induz à questão central desse estudo: 
quem são esses sujeitos? Dimoulis (2013) e Zippelius (2006) trazem contribuições para responder essa questão.

Dimoulis (2013, p.215) inicia sua abordagem reforçando a origem latina da palavra sujeito, indicando "o indivíduo ou grupo que é submetido ao poder de outrem, ou seja, designa uma situação de subordinação, de submissão". Na filosofia, o termo adquiriu um segundo sentido: "passou a indicar o ser humano que pode raciocinar e agir livremente, tendo a capacidade de dominar as coisas e o mundo. O sujeito transforma-se em elementos que domina os objetos". Tem-se, portanto, uma ambiguidade: o sujeito é submetido (assujeitado), ao mesmo tempo em que é capaz de dominar as coisas e o mundo. Na área jurídica, o termo sujeito de direitos indica o titular de um direito, que ao mesmo tempo em que domina, exerce um poder, também impõe vontade e preserva interesses.

Dimoulis (2013) reforça que cabe unicamente ao ordenamento jurídico conferir essa qualidade a alguém, sendo, portanto, um artifício que não decorre de nenhuma condição intrínseca aos indivíduos. Trata-se antes de um ato de escolha política de uma comunidade juridicamente organizada. Ademais, Dimoulis (2013, p. 216) reforça a afirmativa de que a figura do sujeito de direitos tem particular importância no ordenamento jurídico das sociedades capitalistas e lembra que no âmbito da Sociologia e da Filosofia do Direito há estudos que analisam de forma crítica o sujeito de direitos, demonstrando sua função ideológica: “o sujeito de direito procura legitimar o sistema capitalista, porque esconde as desigualdades sociais e a realidade da exploração, da dominação e da discriminação atrás da suposta liberdade e igualdade de todos". São, portanto, leituras externas ao Direito que propiciam a aptidão para formular críticas e superações no Direito.

Zippelius (2006, p. 59 e ss) põe em discussão o tema da pessoa no direito com a seguinte questão: "Vimos que o Direito regula o comportamento humano, mais exatamente prescrevendo ou proibindo condutas. Quem pode desempenhar um papel nesse conjunto de comportamentos normativamente dirigidos e coordenados?". Dessa forma, identificaremos os envolvidos a partir de outras três questões: "quem pertence à comunidade jurídica e para quem (principalmente em favor de quem) devem valer as competências e prescrições de um determinado ordenamento jurídico?”. Segunda questão: “a quem pode ser juridicamente vedado um determinado comportamento, ou seja, quem pode ter obrigações jurídicas (e os direitos correspondentes)?”. E por fim: "quem pode, com seu comportamento, criar, modificar ou extinguir obrigações jurídicas em relação a si ou a terceiros?". Para obter as respostas, 
Zippelius busca o ordenamento alemão. São as perguntas, entretanto, que interessam para a hipótese desse estudo.

O simples desdobramento em questões para que se possa definir quem são os sujeitos de direitos resolve um dos problemas mais singulares da história do Direito brasileiro: a condição dupla do escravo no Brasil no séc. XIX. Simultaneamente era homem e coisa. Podia ter vedado um comportamento, ou seja, era considerado homem, sujeito de direitos para fins de sanção pelo direito penal: roubava, matava, fugia. Mas não podia firmar relações jurídicas em relação a si e a terceiros, pois era mercadoria, um não sujeito de direitos no campo das relações civis e comerciais, nos quais era objeto de compra e venda, podia ser dado em garantia e mesmo locado para ganho do seu dono, como uma ferramenta. Como lembra Schwarz (2000, p.14), "sendo uma propriedade, o escravo podia ser vendido, mas não podia ser demitido" e como, sendo herança, estava fortemente misturado à vida familiar, restava impedida a introjeção do individualismo burguês, que é pressuposto para a afirmação de direitos, ao tratamento jurídico dos escravos.

Um dos ditos conceitos jurídicos fundamentais, portanto, o de sujeito de direitos, não pode ser explicado e compreendido em uma perspectiva reducionista. Até porque, ao citar as definições operacionais mais tradicionais de sujeito de direitos extraídas da literatura jurídica pátria, foi afirmado que as mesmas são um legado da moderna doutrina civilista alemã. Na modernidade, segundo Moreira (2003, p.144), os sujeitos constituem "uma ordem estatal marcada pela associação entre livres e iguais definida em termos jurídicos". Uma associação entre pessoas pressupõe o reconhecimento do eu e do outro. Assim, firmada a necessidade de ampliação do olhar para a compreensão do que são sujeitos de direitos, será examinado de que modo a literatura participou da construção (ou invenção) dos direitos humanos na trajetória de afirmação (ou estabelecimento) das condições subjetivas de aceitação do discurso jurídico moderno fundado na liberdade e na igualdade definida em termos jurídicos. Antes, serão examinadas as noções de bilateralidade, alteridade e identidade como categorias essenciais para a elaboração do discurso jurídico moderno.

\section{A INSTITUIÇÃO DO EU E DO OUTRO}

Esse item explora os conceitos de bilateralidade, identidade e alteridade, categorias que são essenciais para compreender o discurso do Direito na modernidade. A noção de bilateralidade é muito cara ao Direito, em especial no estudo da norma jurídica. De acordo com Reale (2001) a nota distintiva essencial do Direito é a bilateralidade atributiva. A ênfase 
está na atributividade: "há bilateralidade atributiva quando duas ou mais pessoas se relacionam segundo uma proporção objetiva que as autoriza a pretender ou a fazer garantidamente algo" (REALE, 2001, p. 51). Trata-se, completa o autor, de "uma proporção intersubjetiva, em função do qual os sujeitos de uma relação ficam autorizados a pretender, exigir, ou a fazer, garantidamente, algo". Para Vasconcelos (1993, p.150) a propriedade de ser bilateral da norma, isto é, sua referibilidade a dois lados, advém da própria natureza do Direito; Vasconcelos propõe como noção essencial ao conceito de direito a "proportio ad alterum" de Tomás de Aquino.

Para Ferraz Júnior (1990, p.176), os elementos caracterizadores da norma são a sua generalidade, o seu caráter abstrato e a bilateralidade. Essa última característica decorre da afirmação de que toda norma estabelece relações jurídicas entre sujeitos. Mas nem todas as normas jurídicas determinam tais relações: há normas que apenas qualificam um sujeito em termos de sua capacidade, assim como a norma que simplesmente prescrevem um regime de governo. Isso significa, para Ferraz Júnior (1990, p.177) que as normas são bilaterais “apenas no sentido da alteridade, isto é, que demarcam as posições socialmente relevantes dos sujeitos. Só com esse significado (alteridade) pode-se se dizer que todas trazem a nota da bilateralidade".

É possível afirmar, pelos três conceitos colhidos em Reale, Vasconcelos e Ferraz Júnior, que o conceito de bilateralidade aparece na doutrina jurídica sem referência à ideia de igualdade. A ideia de igualdade moderna se dá no campo do seu reconhecimento jurídico ou no "todos são iguais perante a lei”. Esse reconhecimento, portanto, exige a afirmação da existência do eu e do outro, para que a diferença se supere por meio da declaração de igualdade perante a lei. É preciso visibilizar o "outro", diante do "eu”. Na Antropologia essa relação será mais bem explorada.

Goffman (2005) inicia seu estudo da representação do eu na vida cotidiana situando essa questão a partir do momento em que um indivíduo chega à presença de outros. Estar na presença imediata de outros é o que suscita a questão da identidade, do "eu". A identidade se constrói a partir do que o indivíduo expressa de si mesmo, no que Goffman (2005, p.12) chama de atividade significativa. Essa identidade não se constrói sem um interesse: "independentemente do objetivo particular que o indivíduo tenha em mente e da razão desse objetivo, será de interesse dele regular a conduta dos outros, especialmente a maneira como o tratam" (GOFFMAN, 2005, p.13). A hipótese de Goffman é a de que esse controle é realizado 
principalmente através da influência sobre a definição da identidade de si perante os outros. A construção da identidade é, portanto, uma importante peça no jogo social que se estabelece em termos de dominação-submissão, ou inclusão-exclusão.

Hannah Arendt, por sua vez, trabalha com a noção de consciência de si para pensar o "eu". Arendt foi notadamente uma pensadora preocupada com a capacidade de pensar e com as condições para isso. A consciência de si, o "eu", surge em Arendt como consequência do exercício da capacidade de pensar. De acordo com Assy (2004, p.39), a característica primária dessa consciência de si é "evocar pluralidade dentro de nós mesmos, a capacidade de criar outro(s) para si mesmo, de imaginar pontos de vista alheios”. Em certo sentido, segue Assy, "essa consciência de si, tal qual a atribuída por Arendt a Sócrates, faz com que nós possamos aparecer também para nós mesmos, trazer alteridade à reflexão, que, apesar de solitária, não é solipsista". E a própria Arendt que traz uma explicação bastante elucidativa para os objetivos dessa pesquisa, ao ensinar que foram os romanos os primeiros que utilizaram o substantivo persona como metáfora:

\footnotetext{
$\mathrm{Na}$ lei romana, persona era alguém que possuía direitos civis, em contraste agudo com a palavra homo, que denotava alguém que não passava de um membro da espécie humana, diferente, sem dúvida, de um animal, mas sem nenhuma qualificação ou distinção específica, de modo que homo, como o grego anthropos, era frequentemente usado de modo desdenhoso para designar pessoas não protegidas pela lei (ARENDT, 2004, p.75).
}

O eu e outro são, portanto, categorias auto referidas e interdependentes, demandando a compreensão do que seja também alteridade. A alteridade, enquanto categoria da Antropologia, significa o caráter daquilo que é outro, bem como o encontro de diferenças. Seu fundamento ultrapassa a identidade de si, pressupondo a existência do "outro". Segundo Damázio (2011, p.222), “a experiência da alteridade implica perceber que o considerado natural (gesto, postura) é algo próprio de cada cultura”. A construção da identidade, por sua vez, se faz por contraste: “a identidade, porém, acompanha a diferença, pois são justamente nas relações de etnias diferentes que as identidades se projetam" (BRITO, 2011, p.47). O reconhecimento da existência do outro, no mais das vezes, foi, e continua sendo, motivo de antagonismos, exploração e até crueldade: "o desigual, na maioria das vezes, é visto na perspectiva de uma humanidade diminuída, ou melhor, de uma humanidade inferior" (BRITO, 2011, p. 49). É nesse processo de negação do outro que se instala o dispositivo jurídico de inclusão-exclusão da condição de sujeito de direitos, ou pessoas (não) protegidas pela lei. 
Como alcançar um estado de reconhecimento do eu e do outro que instale uma relação de solidariedade entre os desiguais, alcançando a audaciosa proposta do "todos são igual perante a lei"? Como reconhecer no outro um sujeito de direitos, ou o direito de ter direitos? A Antropologia propõe a instalação de práticas alteritárias, por meio de uma valorização da diversidade, o que envolve pôr-se no lugar do outro. Todorov (1988, apud Damázio, 2011, p.223) afirma que "é falando do outro (dialogando com ele e não lhe dando ordens) que reconheço nele uma qualidade de sujeito, comparável ao que eu mesmo sou". Assim, como resposta provisória, ou hipótese dessa pesquisa, afirma-se que esse reconhecimento do outro e a instalação de práticas alteritárias somente são possíveis se eu puder ser o outro, ainda que por alguns instantes. É nessa hipótese que se configura a missão ou o papel da literatura engajada, uma vez que se defende nesse estudo que, por meio da literatura, o "eu" tem oportunidade de ser o "outro".

Assim, cumpre examinar a aptidão da literatura para o reconhecimento e ampliação de direitos a sujeitos de múltiplas identidades.

\section{A LITERATURA COMO MISSÃO}

O título desse item foi tomado de empréstimo do livro homônimo de Nicolau Sevcenko (1985). Trata-se de uma obra que investiga o escritor e a ética ativista, que faz da literatura o registro de uma missão, cumprida a despeito de muitas contrariedades. Nesta ética ativista, o exercício intelectual é tomado como atividade política que investiga os fundamentos sociais e busca uma identificação profunda entre todos os seres humanos. A proposta metodológica de Sevcenko orientou a escrita deste artigo; no caso do livro "Literatura como missão", Sevcenko a aplica para analisar a obra de Euclides da Cunha e Lima Barreto, considerados como dois escritores que influenciaram a vida social e a política no Brasil da primeira República. A mesma perspectiva investigativa encontra-se também em Hunt (2007), ao afirmar que a literatura romântica do séc. XVIII, de Richardson e Rousseau, estava orientada para a busca de adesão ao nascente discurso afirmativo dos Direitos Humanos.

Para Sevcenko (1985, p.79), os processos de transformações sociais de grandes proporções que se deram de forma acelerada tiveram consigo protagonistas de uma produção literária a altura dos acontecimentos: "o engajamento se torna condição ética do homem de letras". Surge o "escritor-cidadão". A chamada literatura utilitária ou engajada emerge como um caminho alternativo para formar opinião. Para essa concepção de escrita literária, somente 
as formas de criação e reprodução cultural que se instrumentalizem como fatores de mudança social são válidas. Funda-se na crença de que a literatura é capaz de produzir novas condições históricas. O impulso lírico dá lugar ao engajamento.

Hunt, por sua vez, propõe uma investigação sobre a invenção dos direitos humanos. Seus eixos de análise são os três textos históricos fundamentais, ou seja, a Declaração de Independência dos Estados Unidos (1776), a Declaração dos Direitos dos Homens e do Cidadão (1789) e a Declaração Universal dos Direitos Humanos promulgada pelas Nações Unidas em 1948. Para Hunt, entretanto, cada conceito embutido nessas declarações é fruto de uma grande luta no plano das mentalidades, nas arenas social e política, com avanços e recuos. Sua metodologia consiste em entrelaçar a filosofia, a crônica política e a história do cotidiano para dar conta desse processo complexo e multifacetado. A autora expõe de que maneira a leitura de romances como Clarissa, de Samuel Richardson, e Júlia ou a nova Heloísa, de Rousseau, ajudou a ampliar o sentimento de empatia pelo destino alheio, em um tempo em que as Declarações de direito conviviam com a escravidão persistente, a dominação ostensiva das mulheres e o desconhecimento do conceito de infância e o reconhecimento de sua vulnerabilidade.

A tese sustentada por Hunt é a de que os Direitos Humanos não proveem da natureza nem estão previamente inscritos em uma ordem metafísica; não surgiram subitamente na consciência dos homens, mas são o resultado (sempre incerto) de um longo (e difícil) processo histórico. Noções como liberdade e igualdade são valores que se consolidaram com a ampla ajuda da leitura de romances aparentemente descomprometidos, que contribuíram para mudanças nas práticas diárias da vida. Foi lendo romances que imaginamos igualdades.

Para a construção desse artigo, foram escolhidas duas obras literárias. Do romantismo carregado e desabrido de Victor Hugo nasceu Jean Valjean, personagem símbolo da humanização das penas. A desagregação interior de Jean Valjean decorre de uma insuspeita e elevada espiritualidade e sensibilidade, em contraste com a mesquinhez da vida material, personificada de modo hiperbólico nos membros da família Thénardier. Do realismo de Jorge Amado desdobra-se um efeito chocante da vida das crianças de rua, ao mesmo tempo em que sensibiliza, enternece e instiga posicionamentos mais solidários. Amado buscava uma literatura que se parecesse com o Brasil, com foco em um grupo social até então ausente da literatura quer de Machado de Assis, quer do próprio Lima Barreto. É uma tentativa de elaboração de ideias que não estivessem fora ou muito longe do cotidiano do povo brasileiro, 
mas sim para fazer o Brasil pensar a si mesmo. Assim, passa-se a análise mais vertical de cada uma dessas obras, nos aspectos que se relacionam a este estudo.

\title{
3.1. "Os Miseráveis": personagens no grande teatro do mundo
}

O prefácio do livro "Os miseráveis”, publicado em 1862, não deixa dúvidas quanto à proposta de Victor Hugo a respeito do papel que a obra e seus personagens deveriam desempenhar na história da literatura universal:

\begin{abstract}
Enquanto, por efeito de leis e costumes, houver proscrição social, forçando a existência, em plena civilização, de verdadeiros infernos, e desvirtuando, por humana fatalidade, um destino por natureza divino; enquanto os três problemas do século - a degradação do homem pelo proletariado, a prostituição da mulher pela fome, e a atrofia da criança pela ignorância - não forem resolvidos; enquanto houver lugares em que seja possível a asfixia social; em outras palavras, e de um ponto de vista mais amplo ainda, enquanto sobre a terra houver ignorância e miséria, livros como este não serão inúteis.
\end{abstract}

A obra e seu personagem mais significativo, Jean Valjean, trazem a miséria para o centro do palco da literatura. Conforme Ribeiro (2002), o espetáculo da miséria é a novidade que romancistas e cientistas sociais apontam como uma herança das guerras, da industrialização e do deslocamento de grandes contingentes humanos do campo para a cidade, nos séculos XVIII e XIX. São muitos os conflitos sociais em torno da miséria. É preciso compreender o peso das lutas sociais, o que ainda não é alcançado, segundo Ribeiro (2002) por Hugo, o que não retira o caráter fundamental da obra: Victor Hugo foi “o maior responsável por se construir, na França e num mundo inteiro que lia e sentia com base na cultura francesa, uma preocupação com a miséria. Com ele, não só se deslancha esse tema, como, além disso, se assume uma fisionomia compassiva, solidária” (RIBEIRO, 2002, p.12). A razão dessa importância reside no olhar o miserável, ser ele objeto do olhar, tornar-se digno de ser visto, de ser um sujeito, tornando-se um "personagem no grande teatro do mundo. Ele passa a ser visto. Passa-se a falar dele" (RIBEIRO, 2002, p.22). De fato, “Os miseráveis" pode ser vista como a grande obra que mudou o modo de olhar para os mais pobres. Mais que isso, foi, segundo Ribeiro (2002, p.25):

\footnotetext{
"uma maneira de negar que os operários sejam perigosos. Podem até parece-lo, na sua fúria justa, mas não o são. Toda uma política de solidariedade com eles, de apoio aos explorados, vai ter nos sentimentos de compaixão, difundidos por Victor Hugo, o seu combustível. Essa política poderá até ser criticada, pelos marxistas, como lacrimosa, piegas, mas ela é fundamental para entender como uma cultura de massas, vendidas aos milhares de exemplares (hoje diríamos aos milhões), passa a tematizar, não só o amor infeliz de ricas herdeiras órfãs, mas a infelicidade das massas trabalhadoras. É muito melhor do que a mania pela segurança pública que, hoje, a mídia constrói."
} 
Com os "Os miseráveis", Victor Hugo desafiou a tentação do impossível: compor um romance sobre a humanidade, com personagens que encarnassem o que temos de melhor - amor, obstinação, esperança em um mundo melhor, coragem e heroísmo, seja em Gavroche, seja em Enjolras - e o que temos de pior - a capacidade de explorar o outro, submetê-lo e reduzi-lo a condição de animal (como ora estão Valjean sob o jugo de Javert, ora Cosette aos cuidados dos Thénardier). O romantismo é um movimento literário que não se furta em expor a parte maldita do ser humano. Toda e qualquer tentativa de descrever a grandiosidade do romance seria, nesse estudo, inócua e inútil. Llosa (2012, p.57) refere-se a Hugo como mentor e consciência de sua sociedade, revolucionário da ética e dos costumes do seu tempo. Tratando da empatia que nos desperta os personagens do romance, Llosa (2012, p.81) destaca o contraste Javert-Enjolras: o primeiro representa a lei e a ordem, e "há qualquer coisa nele que nos é profundamente antipática, mesmo reconhecendo que sua função é imprescindível para a nossa sobrevivência em comunidade", enquanto o segundo encarna o heroísmo fanático, disposto a sacrificar a vida por um ideal humanitário, pelo que se chegou a pensar em "Os Miseráveis" como um romance socialista.

É Llosa (2012, p.99) que também nos lembra de que "uma das cenas mais inesquecíveis do romance precede o resgate do Cosette, por Jean Valjean, das mãos dos Thénardier". A sequência se passa numa tarde que vai virando noite e na qual toda a crueldade do casal com a menina se inscreve: vestida de farrapos, com o olho inchado por causa de um soco da taverneira, Cosette é mandada buscar água atravessando um bosque já quase nas trevas:

\begin{abstract}
Ali, enquanto a menina, curvada pelo peso do balde e morta de pavor, avança quase às cegas, chega a sua libertação, com o providencial encontro com o gigante anônimo que, sem dizer uma palavra, apanha o balde e aperta sua mão, transmitindo-lhe uma promessa de segurança e de amor que mudará radicalmente seu destino. Lenta e cerimoniosa cena, temperada com todas as especiarias do folhetim romântico e que, pela sábia dosagem dos seus ingredientes, nos avassala emocionalmente, aniquilando nossa consciência crítica. (Llosa, 2012, p.99)
\end{abstract}

Prosseguindo seu estudo sobre "Os miseráveis", Llosa reconhece a maneira como esta ficção literária repercute na vida dos leitores e na marcha da sociedade, em parte pela ambição desmesurada de Hugo em construir um romance que por suas dimensões parece competir de igual para igual com a realidade, contrapondo à vida uma ficção "total". Mas também pelo fato de que, em escalas variadas:

“[...] todas as ficções fazem o leitor viver o impossível, tirando-o do seu eu particular, ultrapassando os limites de sua condição, e fazendo-o compartilhar, identificando com os personagens da ilusão, uma vida mais rica, mais intensa, ou 
mais abjeta e violenta, ou simplesmente diferente daquela em que estão confinados nesta prisão de segurança máxima que é a vida real. As ficções, afinal, existem por isso e para isso. Porque só temos uma vida, e os nossos desejos e fantasias nos exigem ter mil. Porque o abismo entre o que somos e o que gostaríamos de ser precisa ser preenchido de alguma maneira. Para isso nascem as ficções: para que, desta maneira vicária, provisória, precária e, ao mesmo tempo, apaixonada e fascinante, como é a vida a que elas nos transportam, possamos incorporar o impossível ao possível e nossa existência seja ao mesmo tempo realidade e irrealidade, história e fábula, vida concreta e aventura maravilhosa". (LLOSA, 2012, p.170, itálico no original)

Llosa (2012, p.173) conclui que talvez não haja como demonstrar que "Os miseráveis" tenha feito a humanidade avançar um milímetro na direção do reino da justiça, da liberdade e da igualdade, mas não há a menor dúvida de que "Os miseráveis" é "uma das obras na história da literatura que mais fizeram homens e mulheres de todas as línguas e culturas desejar um mundo mais justo, racional e mais belo do que aquele em que viviam”. Se a civilização não é um mero simulacro retórico e sim uma realidade capaz de fazer a barbárie retroceder, deve-se algo do ímpeto que possibilitou tudo isso à "nostalgia e ao entusiasmo contagiados nos leitores pelas gestas de Jean Valjean e monsenhor Bienvenu, de Fantine e de Cosette, de Marius e Javert e de todos os que os seguem na sua viagem em busca do impossível".

Victor Hugo, sua literatura e seus personagens, da maneira figurada e simbólica própria da literatura, foram protagonistas do movimento reformista penal, humanizando as penas, e traduziram a pobreza e o desamparo de grandes setores da população. Sem deixar de mencionar o inesquecível Gavroche, com o qual Hugo inscreve de forma definitiva a questão dos pivetes ("gamain") na ordem dos problemas sociais do mundo moderno, este estudo se ocupará agora dos meninos do Brasil.

3.2. "Capitães d'areia", o Código de Menores e o reconhecimento dos direitos das crianças e adolescentes

Pode-se afirmar que "Capitães d'areia", ao lado de outras obras literárias de Amado (como a trilogia "Os subterrâneos da liberdade", formado pelos livros "Ásperos tempos", “Agonia na noite" e "Luz no fim do túnel”), busca inserir a sociedade brasileira numa ordem humanitária, aliada a um compromisso com a originalidade nacional, afim de que o Brasil compartilhasse, em igualdade de condições, de um lugar no mundo dito civilizado. Nesse sentido, criando um bando tão poderoso simbolicamente quanto Oliver Twist e sua turma, de Dickens, Amado nos apresenta os capitães d'areia e impõe um novo olhar sobre os nossos meninos e meninas das ruas, das areias das praias. A força literária de personagens como Pedro Bala, o Professor e Dora, reside nas qualidades morais desses pequenos habitantes do 
submundo: a coragem de Bala, a sabedoria do menino Professor, a doçura e o cuidado de Dora, mãe de todos os meninos do trapiche. No bando, não há traição: "tudo é regido por uma lei e uma moral, por códigos de lealdade e solidariedade" (HATOUM, 2008, p.274). É no espanto de descobrir "neles" as qualidades que queremos para "nós" que reside a força e a longevidade da obra.

“Capitães d'areia” foi censurado e queimado em praça pública, em Salvador, em 1937, ano de seu lançamento. É um romance que ainda comove, como lembra Hatoum (2008, p.274), para quem o livro "antecipou de um modo lúcido e incisivo a vida das crianças que esmolam nas ruas das cidades brasileiras". Tratava-se de provocar no leitor emoções primárias de terror, piedade e admiração, por meio de recursos típicos e atípicos da literatura: “lirismo e crítica social também andam juntas em Capitães d'areia, onde não faltam peripécias romanescas, aventuras de toda sorte, e um pendor à idealização de tipos humanos humildes e desvalidos" (HATOUM, 2008, P.275).

O episódio da queima dos livros está ligado ao controle da opinião pública que se instalava no Brasil com o regime de 1937, o Estado Novo getulista. Para formular uma ampla adesão ao governo, censuravam-se os meios de comunicação e criava-se uma versão oficial da fase histórica que o país vivia. O DIP - Departamento de Imprensa e Propaganda - exerceu funções bastante extensas de proibir a divulgação de críticas ao cenário político e social por meio de quaisquer dos canais comunicativos, "incluindo cinema, rádio teatro, imprensa, literatura social e política" (FAUSTO, 2013, p.322). Exemplares da obra também foram apreendidos das livrarias nos Rio de Janeiro. Em 1937 terminava a primeira década de vigência das leis consolidadas de assistência e proteção aos menores, o primeiro Código de Menores do Brasil, o chamado Código Mello Mattos (Decreto n ${ }^{\circ}$ 17943-A, de 12 de outubro de 1927).

A preocupação da legislação era com a criminalidade juvenil. Acreditava-se que por detrás do pequeno delinquente se ocultava o futuro facínora. No Brasil instalava-se uma perspectiva higienista, com o viés da eugenia: "a cidade estava infestada por crianças que vivem do furto" (AMADO, 2008, p.11). O Direito tinha seus mecanismos próprios para conter o problema do menor "em situação irregular", tido como ameaçador aos destinos da nação. No afã legislativo, procurou-se superar a dicotomia entre menor abandonado e menor delinquente, numa tentativa de ampliar e melhor explicar as situações que dependiam da intervenção do Estado. O Poder Judiciário cria e regulamenta o Juizado de Menores e suas 
instituições auxiliares. O Estado assume o protagonismo como responsável legal pela tutela da criança órfã e abandonada (que não tinha habitação certa) que fica, assim, institucionalizada.

Com sua literatura, Amado buscou uma conscientização quanto à gravidade das precárias condições de sobrevivência das crianças pobres: havia epidemias e abandonos, e era elevada a taxa de mortalidade infantil. As instituições encarregadas da proteção aos menores são duramente denunciadas. O tratamento dado pela imprensa local está comprometido em marginalizar as crianças, montando-lhes uma imagem de delinquentes perigosos, clamando por providências urgentes da policia e do juizado de menores no sentido da "extinção desse bando e para que recolham esses precoces criminosos, que já não deixam a cidade dormir em paz o seu sono tão merecido, aos Institutos de reforma de crianças ou às prisões" (AMADO, 2008, p.11). Rabelo e Nascimento (2014) reforçam o fato de que a narrativa de Amado torna perceptível o medo e o temor que os capitães d'areia tinham de serem apreendidos e levados aos reformatórios, destacando a seguinte passagem: "Castigos... castigos... É a palavra que Pedro Bala mais ouve no reformatório. Por qualquer coisa são espancados, por um nada são castigados. O ódio se acumula dentro de todos eles" (AMADO, 2008, p. 214). E ressaltam a possibilidade de prisão perpétua no Código menorista, "visto que a criança e o adolescente eram submetidos a um juízo de periculosidade, sendo submetidos a reexames periódicos, sob fundamento filantrópico" (RABELO E NASCIMENTO, 2014, p.10). Ao completar 21 anos, se não estivesse apto a reingressar no convívio social, o agora adulto seria submetido ao Juízo de Execução Penal, até que o juiz julgasse extinto o motivo da intervenção.

“Capitães d'areia” buscava realizar a proeza de fazer com que as elites fizessem um meio giro sob seus próprios pés e voltassem o olhar do Atlântico para o interior da própria nação, seja para o sertão, seja para o subúrbio ou para seu semelhante nativo, mas de qualquer forma para o Brasil e não mais para Europa. "Capitães d'areia” é um livro sobre o desamparo e o abandono das crianças brasileiras, mas não se trata apenas de um "registro social de uma época ou lugar específico, mas de uma obra literária que habilmente evoca um drama humano que ainda perdura" (HATOUM, 2008, p.278). Suas questões, como se vê no atual debate da redução da maioridade penal no Brasil, são atemporais.

\section{CONSIDERAÇÕES FINAIS}

O objetivo deste artigo era demonstrar, no curto espaço deste gênero textual, que a compreensão de conceitos fundamentais ao Direito não será alcançada se o olhar se 
concentrar apenas nas formas jurídicas. A literatura é uma ferramenta poderosa no alcance não somente das circunstâncias históricas que se impunham ao tempo do estabelecimento de direitos, mas também na compreensão do esforço de escritores e escritoras que direcionaram seu ofício de escrever para realizar transformações na ordem vigente.

Foram respondidas as questões sobre o que a literatura é capaz de despertar em nós e como contribui para a leitura do mundo que nos rodeia. Por todo o exposto, pode-se afirmar com segurança que, por meio da literatura, é possível ver o que de outra forma não se veria, como as condições (econômicas, sociais, morais, religiosas) distintas dos que são distintos entre si. A experiência sensorial da leitura, o despertar de emoções de empatia ou repúdio, a formação de uma memória, a construção da sensibilidade, são tarefas aptas a serem cumpridas pela literatura na constituição necessária das categorias do eu e do outro.

Se a ficção for bem sucedida, cumpre a função de ser instrumento para que se inquietem os leitores e, por suas páginas, um romance pode se transformar, por seu poder de persuasão, numa força perturbadora da ordem social, econômica e jurídica vigentes, como, em vários momentos de virada da humanidade, os romances aqui estudados, se não foram capazes de subverter a ordem vigente, ao menos foram capazes de inquietar profundamente. Não é à toa que regimes políticos fechados, sob uma orientação teológica ou não, sempre tiveram temor a certos manuscritos, que desestabilizam o espírito e abalam a fé. Não é arriscado afirmar que todas as ditaduras do mundo impuseram sistemas de censura à criação literária, convencidas de que a livre circulação de ideias poderia fazer erodir a disciplina e a obediência imposta pelo temor. Certos livros são como minas, no dizer de Llosa, e podem explodir no espírito e na imaginação do leitor. Especialmente na fundação de si, do eu, e no reconhecimento do outro.

\section{REFERÊNCIAS}

AMADO, Jorge. Capitães d'areia. Posfácio de Milton Hatoum. São Paulo: Companhia das letras, 2008.

ASSY, Bethânia. "Faces privadas em espaços públicos": por uma ética da responsabilidade. In: ARENDT, Hannah. Responsabilidade e Julgamento. Hannah Arendt; edição Jerome Kohn; revisão técnica Bethânia Assy e André Duarte; [tradução Rosaura Einchenberg]. São Paulo: Companhia das Letras, 2004.

ARENDT, Hannah. Responsabilidade e Julgamento. Hannah Arendt; edição Jerome Kohn; revisão técnica Bethânia Assy e André Duarte; [tradução Rosaura Einchenberg]. São Paulo: Companhia das Letras, 2004. 
BRITO, Antônio José Guimarães. Etnicidade, alteridade e tolerância. In: COLAÇO, Thais Luzia (org). Elementos de Antropologia Jurídica. São Paulo: Conceito editorial, 2011.

DAMÁZIO, Eloise da Silveira Petter. Antropologia, alteridade e direito: da construção do "outro" colonizado como inferior a partir do discurso colonial à necessidade da prática alteritária. In: COLAÇO, Thais Luzia (org). Elementos de Antropologia Jurídica. São Paulo: Conceito editorial, 2011.

DIMOULIS, Dimitri. Manual de introdução ao estudo do Direito: definição e conceitos básicos. 5. ed. rev. atual. e ampl. São Paulo: Revista dos Tribunais, 2013.

FAUSTO. Boris. História do Brasil. 14. ed. atual. e ampl. São Paulo: EdUSP, 2013. FERRAZ JÚNIOR, Tércio Sampaio. Introdução ao Estudo do Direito - técnica, decisão, dominação. 1 ed, 3. tir. São Paulo: Atlas, 1990.

GOFFMAN, Erving. A representação do eu na vida cotidiana. 13. ed. Petrópolis: Vozes, 2005 .

HATOUM, Milton. Posfácio: in AMADO, Jorge. Capitães d'areia. São Paulo: Companhia das letras, 2008.

HUGO, Victor. Os miseráveis. Apresentação: Renato Janine Ribeiro. Tradução: Frederico Ozanam Pessoa de Barros. São Paulo: Cosac Naify, 2002.

HUNT, Lynn. A invenção dos direitos humanos: uma história. Trad. Rosaura Eichenberg. São Paulo: Companhia das Letras, 2009.

LLOSA, Mário Vargas. A tentação do impossível: Victor Hugo e Os miseráveis. Trad. Paulina Wacht e Ari Roitman. Rio de Janeiro: Objetiva, 2012.

MACHADO, Hugo de Brito. Introdução ao estudo do Direito. 3. ed. São Paulo: Atlas, 2012.

MERLE, Jean-Christophe; MOREIRA, Luiz (org). Direito e Legitimidade. São Paulo: Landy, 2003.

MONTORO, André Franco. Introdução à ciência do Direito. 31. ed. rev. e atual. São Paulo: Revista dos Tribunais, 2014.

RABELO, Janaína da Silva. NASCIMENTO, Maria Daniele Silva do. Adolescentes em conflito com a lei na obra Capitães d'areia de Jorge Amado. In: Direito, arte e literatura [Recurso eletrônico online] organização CONPEDI/UFSC; coordenadores: Marcelo Campos Galuppo, André Karam Trindade, Luiz Carlos Cancellier de Olivo. Florianópolis: CONPEDI, 2014. Disponível em: < http://www.publicadireito.com.br/artigos/?cod=e0d1b5ce9153ef87>. Acesso em 01. jul.2015.

REALE, Miguel. Lições preliminares de Direito. 25. ed. São Paulo: Saraiva, 2000.

RIBEIRO, Renato Janine. Apresentação in: HUGO, Victor. Os miseráveis. Tradução: Frederico Ozanam Pessoa de Barros. São Paulo: Cosac Naify, 2002. 
SCHWARZ, Roberto. Ao vencedor as batatas: forma literária e processo social nos inícios do romance brasileiro. 5. ed. São Paulo: Duas cidades; ed. 34, 2000.

SEVCENKO, Nicolau. Literatura como missão: tensões sociais e criação cultural na primeira república. 2. ed. São Paulo: Brasiliense, 1985.

VASCONCELOS, Arnaldo. Teoria da norma jurídica. 3. ed. São Paulo: Malheiros, 1993.

ZIPPELIUS, Reinhold. Introdução ao estudo do Direito. Tradução: Gercélia Batista de Oliveira Mendes. Belo Horizonte: Del Rey, 2006. 